\title{
Reframing the governance of automotive automation: Insights from UK stakeholder workshops
}

\author{
Tom Cohen, Jack Stilgoe and Clemence Cavoli
}

Keywords

Self-driving cars; autonomous vehicles; governance; stakeholder workshops; anticipatory governance

\section{Funding details}

This work was supported by a contract from the UK's Department for Transport

\begin{abstract}
How should policymakers engage with the possibilities of self-driving cars? There has been prominent discussion of proposed benefits and safety concerns. However, considering the scale of investment and speed of development, the social complexity of systems involving self-driving cars has received inadequate attention. Self-driving cars are currently being tested on open roads. The anticipation necessary for good governance can be informed only in part by such experiments. There is a need to broaden the set of issues that are considered relevant. In this paper, we report on the first systematic process of engagement with stakeholders in the UK. We organise the findings of these workshops in terms of questions that might inform the ongoing debate about the governance of self-driving cars. These questions are grouped under four headings: technological and market developments, use of and reaction to technology, wider impacts and the role of the public sector. Our conclusion is that this debate urgently needs to be broadened in order to build trustworthiness and maximise the public value of this emerging technology. The possibilities of self-driving cars suggest the need for a more active form of governance for responsible innovation.
\end{abstract}

\section{Introduction: Anticipation, experimentation and emergence}

In his prescient 1980 book The Social Control of Technology, David Collingridge describes an early attempt at what might now be called 'real-time technology assessment' (Guston and Sarewitz 2002). In the early 1900s, sensing (correctly) the imminent explosive uptake of the automobile, the British Government asked a Royal Commission to advise on regulation. This new technology was starting to become a common sight. In the words of one parliamentarian, cars were 'becoming less unpopular every day'1. The first cars were made to fit into social norms and horses took precedence. The 1865 Locomotive act mandated UK speed limits of $2 \mathrm{mph}$ in cities and $4 \mathrm{mph}$ in the countryside. The 'Red Flag' law that had demanded all motorcars be preceded by pedestrian with a warning signal was repealed at the end of the $19^{\text {th }}$ Century, but the motorcar still generated considerable concern. The Royal Commission's report got some things right. It recommended that drivers who were found to be drunk should be penalised, for

${ }^{1}$ Lord Willoughby de Broke, Hansard, 29 July 1908

http://hansard.millbanksystems.com/lords/1908/jul/29/motor-car-legislation 
example. ${ }^{2}$ However, its foresight was, to put it charitably, partial. The major issue identified by the inquiry was that of dust clouds kicked up by wheels, which one parliamentarian who acted as a witness to the commission in 1906 suspected was 'the cause of nine-tenths of the unpopularity of the motor cars' (quoted in Bagwell 2002). The solution was to impose speeding fines, using the money to upgrade roads. Warnings that these roads would increase traffic went unheeded.

As Collingridge puts it, 'with hindsight we smile, but only with hindsight' (Collingridge, 1980: 16). The car would go on to become one of the most transformative technologies the world had ever seen. ${ }^{3}$ Could the experts of the day have been expected to predict the myriad ways in which the motorcar would reshape $20^{\text {th }}$ Century lives, societies and landscapes?

In 1963, the UK had 7 million cars on its roads. The Ministry of Transport commissioned a report from Sir Colin Buchanan, which reflected, in language that is unusually poetic for a government report, public ambivalence towards the technology:

'We are nourishing at immense cost a monster of great potential destructiveness. And yet we love him dearly. Regarded in its collective aspect as 'the traffic problem' the motor car is clearly a menace which can spoil our civilisation. But translated into terms of our own car, we regard it as one of our most treasured possessions or dearest ambitions, an immense convenience, an expander of the dimensions of life, an instrument of emancipation, a symbol of the modern age.' (Buchanan, 1963)

This 'instrument of emancipation' is implicated in more than 1.2 million deaths per yeari. It has enabled dramatic increases in mobility, but the technological novelty of cars' primary function does little to explain the disruption they have enabled. Traffic congestion is just one example of an emergent phenomenon that is more than just an aggregation of individual technologies. Societies are locked in to the sociotechnical system of automobility (Urry, 1999, after Hughes 1993). Nye (2007, p. 55) concludes that 'the automobile achieved technological momentum not as an isolated machine, but as part of a system that included road building, driver education programs, gas stations, repair shops, manufacturers of spare parts and new forms of land use that spread out the population into the suburbs'. Awareness of the unintended consequences of cars including injury and death, congestion, pollution and sedentary lifestyles - lagged behind the immediate recognition of their benefits. By the 1960s, when more than third of the US population owned a car, urban landscapes in places like Los Angeles had already been designed around a dependence upon cars.

For the Royal Commission, the complexities of this emergent sociotechnical system were hard to anticipate and road dust represented a solvable problem - a risk to be mitigated and managed. Collingridge (1980) demands that we ask the far more important but far

\footnotetext{
2 The level of inebriation was not quantified in the report

3 Writing in 1980, Collingridge guessed correctly that the personal computer would be similarly transformative, although he resisted the temptation to predict the ways in which its effects would be felt.
} 
harder question of how emerging sociotechnical systems are solidified, and what can be done to govern them in the public interest.

As excitement grows around self-driving cars or, to use one common name for the more general category, 'Autonomous Vehicles' (AVs) ${ }^{4}$, the debate about both their benefits and unintended consequences has been dominated by questions of risk. AVs are seen as capable of overcoming the imperfections of human drivers, who are blamed for around 90\% of the crashes (Anderson et al., 2014a; McCarthy et al., 2015; Bertoncello and Wee, 2015; Fox, 2016). At the same time, the novelty of these vehicles' control mechanisms suggests the possibility for new forms of risk caused by algorithmic imperfection or vulnerability to hacking (Frisoni et al., 2016; Wolmar, 2016; Bierstedt et al 2014; DiClemente et al., 2014; Feng et al., 2014; Fagnant and Kockelman 2013).

As with the motorcar in the $20^{\text {th }}$ Century, many of the most profound social changes that will be wrought by self-driving cars will not relate to the lives they take or the lives they save, but rather to the sociotechnical systems that will emerge around them. These changes will not just relate to how we drive or are driven, but also to how we live, how we work and how we build our environment. As Collingridge (1980) highlights, predicting the magnitude (or even the direction) of such changes is impossible to do with certainty. However, it remains vital to anticipate the broad possibilities for future developments of transport systems containing AVs. The broad societal ramifications of transport systems involving self-driving cars are currently under-researched and governments have not yet begun to connect possibilities of these technologies with their strategies for future transport.

Despite numerous claims that self-driving cars are 'just around the corner', they are currently highly experimental technologies, even if their laboratories are, in some cases, public roads, as with the trials taking place in and around Phoenix, Arizona. As such, they are amenable to the rich insights from social science relating to emerging technologies and responsible innovation. However, the case of self-driving cars reveals some gaps in current studies of responsible innovation. In opening up discussions of the opportunities and uncertainties of this technology, we see clearly the need to draw lines between emerging technology and the sociotechnical systems that it enables, but which also depend on myriad other constituent parts. A fundamental challenge lies in linking experimentation to anticipation.

The aim of this paper is to broaden the debate on the governance of self-driving cars and, by doing so, stretch the ambitions of debates around responsible innovation. Without attempting to predict what a driverless future will look like, we hope to draw attention to a set of currently neglected questions as a foundation for a constructive discussion on technology governance. The source for our insights is a pair of workshops conducted with approximately 80 stakeholders in 2016, as part of a project supported by the UK Department for Transport, a complete account of which is in a final report (Cohen et al

\footnotetext{
${ }^{4}$ This term is problematic, given both the socially-constructed nature of the technology (cars will remain 'driven' by human desires even if these are filtered only through human-designed algorithms) and the differing levels of connectivity imagined in different visions of the technology (see Stilgoe 2018; Stayton 2015). In this paper, we use the term as shorthand for a range of fully or partly automated vehicles, with different degrees of autonomy and connectivity.
} 
2017). Based on this evidence, we conclude by offering a new vision for the role of public bodies in shaping self-driving futures.

\section{Responsible governance and emerging sociotechnical systems}

Recent ideas, policies and practices of responsible research and innovation begin with the recognition that science and technology have the power to shape futures that distribute benefits, risks, opportunities and uncertainties unevenly. The lines of responsibility that should accompany such power have historically been poorly drawn. This 'organised irresponsibility' (Beck 1995) is exacerbated by the networked, emergent nature of innovation.

The institutional response to such concerns has conventionally been to hone our systems of risk management and ethical oversight. However, there is a growing realisation, informed by research in Science and Technology Studies, that these mechanisms overlook a more profound set of 'upstream' questions (Wynne 2002). When Sheila Jasanoff $(2003,224)$ asks 'Is it sufficient, for instance, to assess technology's consequences, or must we also seek to evaluate its aims?' it is clear that her question is rhetorical. She suggests that science and innovation should be scrutinised according to the 'questions we should ask of almost every human enterprise that intends to alter society: what is the purpose; who will be hurt; who benefits; and how can we know?' (Jasanoff 2003, 240).

Efforts to organise such interrogation have recently been reformulated in terms of 'responsible innovation' (Stilgoe et al 2013) or 'responsible research and innovation' (von Schomberg 2013). Extending models of anticipatory governance (Guston 2014), frameworks of responsible innovation attempt to build capacity for anticipation, inclusion, reflexivity and responsiveness in sociotechnical systems (Stilgoe et al 2013). Responsiveness is seen as particularly important and commonly neglected in public deliberations, which often run up against de facto governance, the dynamics that shape science and innovation in particular ways and constrain attempts to alter course towards greater public value (Rip 2006; Miller and Neff 2013).

When stakeholders and other publics are given the opportunity to engage in upstream discussions of emerging technology, their insights can be powerful and expansive. Such deliberation, according to Callon (1998), typically 'overflows' the edges that are drawn in its framing. And yet the more such discussions expand, the more powerless they seem. In a recent argument, Jasanoff (2016) takes issue with the mismatch between deliberative governance initiatives and the distribution of power in innovation:

'Could current practices of responsible innovation and anticipatory governance have turned the tide of the automobile's history before it took a tragic course?... For all practical purposes, the power to set the rules of the game for governing technology rests with capital and industry, not with the political representatives of the working, consuming and too often suffering masses.'

The four characteristics of responsible innovation described above - anticipation, inclusion, reflexivity and responsiveness - can be translated into an iterative attempt to build scientists' and engineers' capacity for responsibility. In the US, under the aegis of 
the Centre for Nanotechnology and Society, the Socio-Technical Integration Research (STIR) project has used embedded social scientists, philosophers and others inside laboratories to probe questions of responsibility, test the capacity for responsiveness and create new possibilities for responsible action (see figure 1).

Figure 1, adapted from Fisher (2015)

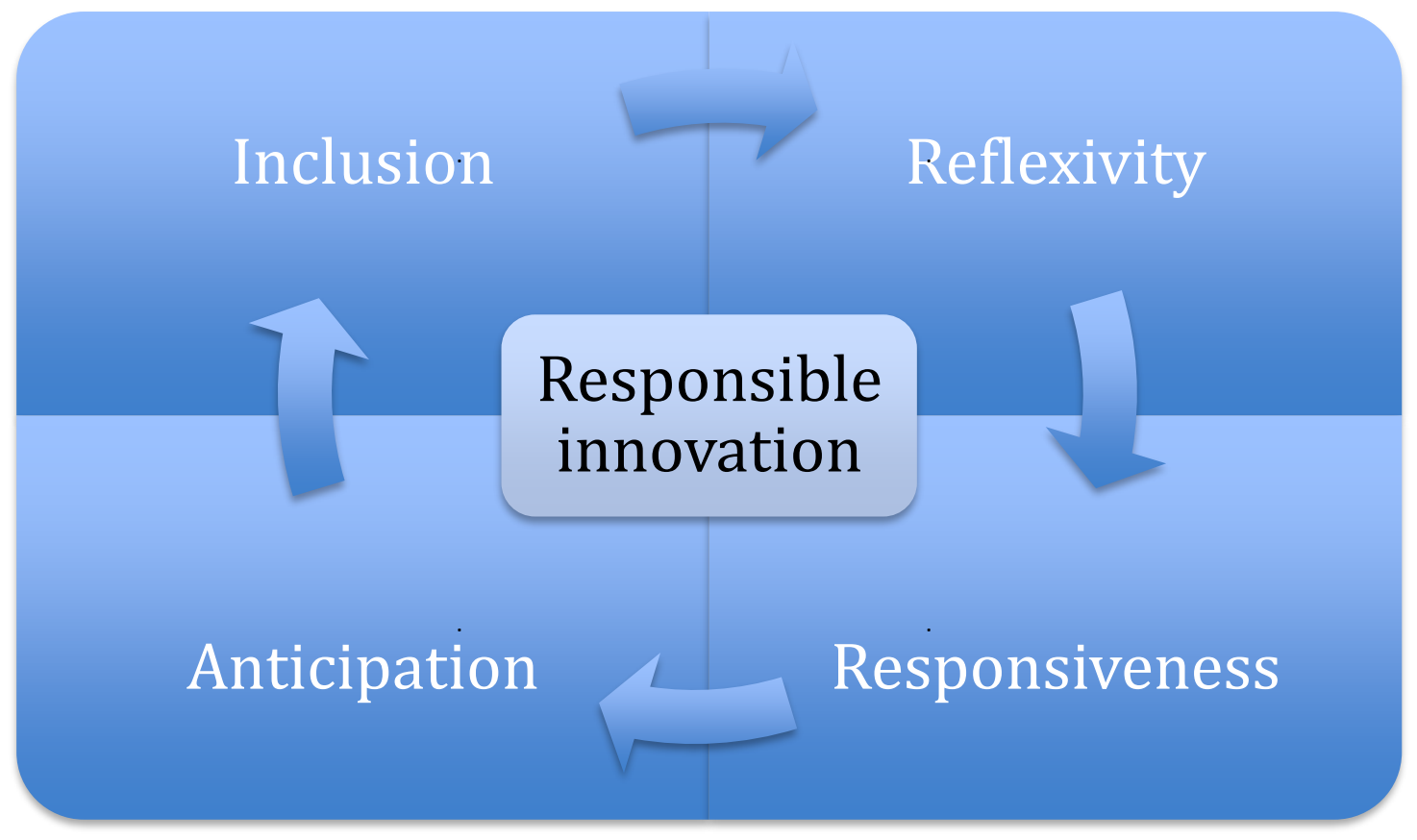

STIR projects and other deliberative efforts to cross laboratory thresholds have had interesting, surprising and often hard-to-quantify impacts (e.g. McTiernan et al 2016). However, in running such conversations, and seeking to nudge governance from de facto, to reflexive, to deliberate (Fisher et al 2006), it becomes clear that the location for necessary action often lies beyond the walls of the laboratory. In deliberative exercises, participants and observers often point to the limitation that the people who should be listening seem not to be in the room. Simply put, the people doing the anticipating are not the same people as those who should be doing the responding. If responsible innovation is to better reflect the reality of emerging sociotechnical systems and engage with questions of power, we should consider how deliberative processes can reach upwards rather than going round in circles.

Rather than simply diagnose a mismatch between anticipation and responsiveness, one might instead see responsible innovation as necessarily multi-level. If on-the-ground experimenting with experimentation is to have purchase, it must connect laboratories and the innovations within them to the regimes that govern these activities and the landscapes in which they take place (following Schot and Geels 2007).

From one perspective, therefore, it may be seen as a problem that public and stakeholder discussions quickly get out of hand. They begin conversations that they can't finish and that can spiral out of control. But, viewed another way, these conversations point at vital connections with political economy that conventional governance often leaves 
untouched. Deliberative processes are, in Irwin's words 'often at their best when expanding issues, raising foundational questions, and linking concerns which the policymaker might view as quite separate' (Irwin, 2016, p. 29).

We can therefore anticipate that broad discussions about AVs will draw important and possibly surprising systemic connections not just to new technological possibilities but also to imagined future transport systems.

\section{Where is self-driving going?}

To anticipate where AVs might go, we should first consider where they have come from. The self-driving car has multiple plausible histories. The first might start with devices, often in high-end cars, designed to make driving easier and safer. Cruise control, for example, has been around for almost 60 years. A 1958 article in Popular Science magazine announced: 'Like it or not, the robots are slowly taking over a driver's chores'. The same article claimed that such technology 'is not easy to explain to women and the mechanically innocent' and expressed a concern that 'with literally nothing to do except steer and ruminate, a driver may fall victim to hypnotic goof-offs. ${ }^{5}$ At around the same time, US car giant General Motors tried to develop an automatic steering mechanism that demanded the installation of guide wires in roads. A 1960 article in Electrical Engineering magazine claimed that 'Highway systems could be in place as early as 1975'. Experiments with automated highways continued but without widespread uptake (Wetmore 2003). More successful innovations included anti-lock brakes, stability control, collision and lane departure warnings (Kröger 2016; Vinsel, forthcoming).

While these features have been a feature of car manufacturers' own Research and Development (R\&D), new entrants to the AV market would argue that the real novelty lay in software rather than hardware. Frisoni et al (2016) call this approach 'revolutionary' as opposed to 'evolutionary'. Companies like Tesla and Alphabet, alongside start-ups who are helping legacy manufacturers to automate their new models, would argue that it is the combination of sensors and machine learning with real-time and geographical data that makes self-driving cars a short-term likelihood (Stilgoe 2017).

A typology from the Society of Automotive Engineers that has been adopted by the US National Highways Transport Safety Administration defines levels of automation from zero to five, with zero being no automation, five being complete automation in all possible circumstances. The implication is that progress means moving up these levels. In reality, there is no single line of progress for AVs. There are competing trajectories and strategies and a large space of possible contingency. The 'social constitution' (GroveWhite et al 2000, Kearnes et al 2006, Szerszynski et al 2013) of self-driving cars is not yet set. Some self-driving innovators such as Uber have made clear their intention to build a model in which on-demand autonomous taxis replace private car use in cities. Meanwhile, established carmakers and younger companies such as Tesla are developing automated driving as a high-spec safety technology in their luxury cars.

\footnotetext{
${ }^{5}$ Rowsome, F, 1958. What It's Like To Drive An Auto-Pilot Car, Popular Science, April 1958 http://imperialclub.com/Articles/58AutoPilot/index.htm
} 
The myriad possibilities of automating transport and the hype surrounding them have led commentators to predict with some certainty that AVs will remove the need for parking, congestion, car insurance and private car ownership (KPMG, 2013; McCarthy et al., 2015). However, one can equally imagine trajectories of innovation in which cars becomes cheaper and more convenient, leading to increased use and congestion, or in which the traffic effects of low-occupancy vehicles are worsened by the growth of zerooccupancy vehicles. The future beneficiaries of AV systems and the dynamics of inequality and transport justice (Martens 2016) are radically indeterminate.

Additional contingencies are introduced through highly uncertain market dynamics. The dimensions of competition between AV companies could include speed, safety, capacity, luxury, reliability, route selection, monetising of user data and privacy. And geographical variation between countries, cities, urban and rural areas could see the success of AVs either underpinning or undermining future public transport systems. As well as imagining future worlds populated by AVs, we can also anticipate the bumpy transitions required to reach them. The journey to whatever future is imagined will be neither straight nor predictable; it may create new risks before benefits are realised.

Our project was designed to create the space for negotiation of such concerns, and others besides, with a view to informing governance. There has been relatively little discussion in either policy circles or scholarly literature of the role of government and public bodies in shaping the future of self-driving car technology. Governments have been largely content to provide public roads as laboratories for the development of vehicle technology and have prioritised the potential economic benefits that might come from investment, jobs and new market opportunities.

\section{Stakeholder workshops and expert interviews}

In 2016, we were commissioned by the UK Department for Transport (DfT) to investigate the major social and behavioural questions surrounding connected and autonomous vehicles and their development. The DfT proposed three areas of study general public attitudes, interactions between AVs and their users and interactions with other road users. To these, we added a third area of investigation - the wider, long-term social, economic and environmental impacts surrounding AVs. The work began with a literature review. We then worked with the three groups that had been funded to run the first trials of AV research and development in four locations across England; this included a half-day workshop. Finally, we ran a process of stakeholder engagement involving two one-day workshops and a set of nine expert interviews.

The workshop with the AV trials involved four representatives from each of the three trial consortia. Each team gave a presentation, for which we asked them to address the question, 'What keeps you awake at night?' We then facilitated discussions on three themes: extrapolation (making inferences about a future in which AVs may be ubiquitous from trials that are limited both by their size and the early stage of the technology); research gaps; and how to enable citizens of the present to imagine and experience a world with AVs.

The stakeholder workshops were planned collaboratively by the study team and DfT officials. A concerted effort was made to identify a wide range of potential participants. 
In particular, we prioritised the inclusion of organisations with interests outside transport. We felt it important to embrace the diversity of organisation types with potential interests in AV innovation, so invitations went to industry (manufacturers, transport providers, insurers, legal etc), central government departments, local authorities, think tanks, charities and campaign organisations, researchers and research funders and regulators. We began with a set of target individuals and organisations, but the eventual attendee list differed somewhat. Several individuals, learning of the events, asked to attend and we welcomed these for the most part, demurring only where we perceived a risk that a particular organisation would be over-represented. Others, particularly from small organisations, felt unable to spare the time, meaning that our workshops could be accused of having a small self-selection bias. This is a common problem with upstream stakeholder engagement work, in which the group who see themselves as relevant stakeholders at an early stage does not completely represent the future groups who may eventually have an interest.

Approximately 40 individuals attended each of the two workshops. The majority were from the transport sector, with government officials (both local and national) the largest group. Smaller numbers attended from industry (mainly bus operators, private hire firms and consultancy) and from the third sector (e.g. lobby groups and charities). There were also several researchers present from higher education institutions. While the dominance of transport, our workshops were also attended by representatives of the Department of Health, the Home Office and the College of Policing.

The thinking behind the design of the workshops was that it was necessary to give participants something meaningful to discuss despite the uncertainties. Asking participants what they thought about AVs would have been unlikely to produce particularly useful outputs. We concluded, therefore, that a degree of provocation was needed. This meant introducing a degree of controversy about the topic. Presenting a wholly positive picture of a world including AVs would elicit much less from participants than confronting them with possibly uncomfortable futures. We worked with the client to arrive at stimulus materials that were challenging while being constructive. We had to tread carefully. The project had multiple sponsors in government who represented a spectrum of positions concerning AVs, including bullish enthusiasm for the technology. All sponsors were willing for the "good-news" story of AVs to be put to the test but there were disagreements about how robust that test should be.

The workshops began with some examples of inaccurate predictions for automobiles and the Internet when these technologies were in their infancy. We also introduced the example of supersonic travel as a technology that was at one time widely expected to become ubiquitous. These historical touchpoints were an attempt to challenge assumptions of inevitability that we felt characterised much AV discussion and acted as a barrier to deliberation. Participants were asked to find alternative entrypoints to the discussion and inject their own diverse values and expertise.

Most of the workshop time was spent in small groups of 6-10 participants. In the first exercise - 'Mapping the Territory' - facilitators explored with participants the likely context within which automation may emerge and the possible interaction with other parts of the system. For example, participants were asked to describe what they thought the technology would look like at maturity and to give their views concerning a set of 
relevant background assumptions relating to urbanisation, demography, prosperity and other trends. They were also asked to reflect on the possible trajectory of deployment: would AVs become dominant or would they lack sufficient buyers in the early stages to give the technology necessary impetus? We also discussed the balance between the market and state control and ran through a force-field analysis (considering the forces for and against change). Each discussion took its own path, with some groups spending longer on the contingencies of deployment and others concentrating more on background assumptions.

The second exercise employed 'scenes', or use cases. A set of 12 was created to serve as provocation for group discussion and each was accompanied by a list of questions that facilitators used to probe the opinions of small groups. The majority of the scenes presented uncomfortable dilemmas or problematic consequences of vehicle automation. The set is summarised in the Appendix but two examples are given here for illustration:

- 'Zero Day' was a newspaper report of an alleged exploit in the firmware of an AV that had revealed the whereabouts of a TV celebrity, leading her to sue the car's manufacturer.

- 'Mayor 'robustly confronted", also a newspaper report, described discord in a county town in which the council was drastically reducing the volume of off-street carparking in response to fully automated vehicles no longer needing to be parked, much to the displeasure of the local AV owners' society.

Following both the Mapping the Territory and scene-discussion sessions, there was a plenary feedback session.

All small-group and plenary discussions were recorded and transcribed. The transcripts were then analysed thematically and a set of questions (explicit or implicit) extracted from the text and allocated to a set of categories and sub-categories. These were subsequently combined with those generated by the literature review and expert interviews and are publicly available (See appendix for a full list of questions).

Interviews were motivated by the desire to represent perspectives that were unable to attend the workshops for some reason. As far as possible, these were conducted in person and were semi-structured, with some standard elements (e.g. asking the participant what they thought the mature form of the technology would be). As the project reported (early 2017) we wrote to those who had participated in some way in the project to notify them that the documentation was available.

\section{A typology of questions and concerns}

We organised the findings of the workshops as a typology of concerns, iterating and refining these in expert interviews and with reference to the literature. As has been observed with previous engagement exercises around emerging technologies (Stilgoe 2007), critical deliberations are better able to articulate questions than answers, as they open up uncertainties behind the futures under discussion. These questions can take various flavours. Some are straightforward demands for information that can be met with relatively easy responses from scientists or engineers. Some point to uncertainties that have been relatively neglected and require further research. Others are more challenging, illuminating areas of ignorance or ambiguity that may be impossible to 
resolve. The majority of those generated in the workshops are either predictive ('what will happen?') or normative ('what should X do?'); normative questions are distinguished by having implicit underlying values. Apart from 'pure' normative questions there are remedial questions ('which interventions might most effectively limit negative/unwanted event Y?') and back-casting questions ('given desired outcome Y/agreed goal of achieving Y, what does agent X need to do?'). The bulk of normative questions that have been gathered in this project (pure, remedial and backcasting) relate to government influence.

Ravetz (1997) has described how, in the early stages of development, it is important to democratise the discussion of 'what-if' questions. Conventionally, such questions are imagined to inspire creativity and innovation. However, a precautionary approach would emphasise the need to also ask 'what if' questions about unintended consequences. With this in mind, we prompted the leaders of the UK's public AV trials to consider negative unintended consequences by asking 'what keeps you awake at night'. In one case, this question was interpreted narrowly, with the team's concerns relating to the success of their project. However, other responses reflected concerns about social exclusion, increased parking, reduced walking, cycling and public transport, new forms of crash, inequality of access, hacking of AV systems, manipulation of vehicles' sensors and backlashes from cycling and/or driving lobbies in a future filled with self-driving cars. Such concerns, and others extracted in the course of our literature review, provided the impetus for our stakeholder engagement.

We organised the more than 350 questions drawn out in the course of our workshops into four categories:

- Technological and market developments - the set of actions and events that would determine future AV possibilities

- Use of and reaction to AVs - how and by whom AVs might be purchased, accessed and used and how other road users will respond

- Wider impacts - the first-order and higher-order impacts of AV use, ranging from network performance to wellbeing

- Public sector's role - the scope for government at all levels to affect the forms of technology, the consequences of uptake and the policy issues that are likely to arise

A conventional linear model of innovation (Godin 2006) would suggest that these categories would emerge as salient in a sequence, starting with technology, through public reaction, impacts and attitudes and finally prompting a regulatory response. However, we know from past emerging technologies such as agricultural biotechnology, new reproductive technologies and energy technologies that the upstream attitudes of users, stakeholders and publics can have downstream implications for the trajectory of innovation (Grove-White et al 2000). Trust in new technologies is fragile and contingent on multiple factors beyond just safety. And technological novelty is no guarantee of market success. The interplay of these issues is therefore unpredictable. So while it is productive in deliberative exercises to talk in the language of technological 'impacts', we should not allow such talk to reinforce an idea of technological inevitability.

These streams of concern can also be seen as operating in the context of some wider dynamics. Global trends such as economic development, urbanisation and the changing 
nature of employment should serve to remind us that AV 'systems' are subject to a wide range of external influences. Anticipating the possible wider impacts of AVs therefore requires assumptions to be made about the other categories. In our stakeholder workshops, we explored the basis for such assumptions and found that almost all had more profound uncertainties than we or our stakeholders had recognised as individuals. These uncertainties, rather than undermining attempts at anticipatory governance, as Nordmann (2014) has claimed, instead provide a rationale for the pluralising of governance debates beyond AV innovators and other experts.

\section{Technological and market developments}

Many of the workshop discussions of technological development began with questions of risk: Would AVs be safer in all circumstances than human drivers? What new risks would be created by AV systems? Would current regulatory structures, built around cars as hardware, have the capacity to govern the intricacies and contingencies of software? Broader questions arising in this category related largely to whether there was a business case for AVs, what functions vehicles would perform and what they would require from their users. In the event of technological failure, what challenges would 'handover' (Morgan et al 2016) from computer to human present? Reflecting the emerging literature (Colwell, 2015; KPMG and Center for Automotive Research, 2012; KPMG, 2015; Felix et al., 2015; Feng et al., 2014), cybersecurity of connected vehicles emerged as a prominent issue, as did data ownership and access (Frisoni et al., 2016). AVs will be data-intensive, connected and therefore vulnerable to system-wide cyberattack. How might governments respond to new threats arising as a result of this new technology? Using an AV will almost certainly imply the surrender of information and will involve giving consent for data use to a combination of public and private entitites.

Following these initial threads, stakeholder participants sought to understand different types of automation and how inclusive these technologies would be: Would they be available to all?; Would the transition to maturity (and possible market dominance) disadvantage users of established technologies? There were concerns about technological pluralism and the maintenance of alternative forms of transport in a world dominated by AVs. There was a further set of questions concerning the need for surrounding infrastructure to respond to the characteristics of AVs, especially in light of expected competition for road space: would those choosing to travel by other means in future be able to co-exist successfully with AVs?

\section{Use of and response to AVs}

The first set of questions in this category related to an obvious but neglected area of uncertainty: the potential demand for AVs. The majority of the workshop participants and most of the literature reviewed expressed confidence that AVs will be promptly developed and rapidly taken up. Clark and colleagues (2016) question the viability of a market for AVs if negative side effects become clear. Possible barriers of affordability, liability costs, lack of business strategy, and lack of consumer demand have been discussed in the literature (Fagnant et al., 2015; Clark et al., 2016).

Some workshop participants were sceptical about the speed of market uptake. The discussions took several directions, the first being mobility: as the demand for AVs 
(presumably) developed, would traffic intensify or might new ownership/use models mean a reduction in overall vehicle-kilometres and a more efficient use of both vehicles and road space? Traffic concerns from low occupancy rates in cars would surely be exacerbated by zero-occupancy AVs.

Participants were concerned that widely asserted safety benefits may rely on optimistic assumptions about operating speeds or segregation of types of road user. Questions emerged about the suitability of AVs for particular road types - motorways, city streets or segregated carriageways, for example - and the extent to which other infrastructure would have to be adapted (Bierstedt et al, 2014). Extending this concern, participants raised questions about the engineering and regulation of AVs across jurisdictions, where rules, norms and cultures of driving differ.

The workshop discussion was deepened by reversing the dominant narrative. Rather than starting with the technology, some stakeholders began with policy and planning goals and questioned how AVs might fit. This provided a means of exploring wider systemic ramifications.

\section{Wider impacts}

The proposed benefits of AVs were quickly challenged by many of the stakeholder participants who had been up to this point less closely engaged with AV debate. Claims about increased efficiency were met with visions of greatly increased demand absorbing and then exceeding capacity. Similar doubts were expressed in the literature (Brown, 2016; Fox, 2016; Guerra, 2015; Bierstedt et al., 2014; LeVine and Polak, 2014; Fagnant et al., 2013). Similarly, assertions of safety benefits were challenged during the workshops with a series of questions about ideal operating environments, AV behaviour around vulnerable road users and running speeds. The slow turnover of the car fleet would limit the potential for rapid realising of purported benefits. The presentation of scenarios in which AVs would herald a greener and cleaner transport system prompted concerns that private transport would crowd out more efficient public transport. These concerns echo multiple authors who warn that the potential energy efficiency gains of AVs may be outweighed by a sharp increase in private car use (Fagnant et al., 2015; Brown et al., 2014) and a decrease in public transport (Wolmar, 2016; Ticoll, 2015).

The possible pressure that AVs will place on infrastructure has received some attention in the literature (International Transport Forum, 2015; Anderson et al., 2014a; KPMG and Center for Automotive Research, 2012). DiClemente and colleagues (2014) state that 'The conversion to a fully automated road infrastructure will be one of the most momentous challenges that humanity will face in the 21st century.' However, such concerns are rarely admitted by innovators, who typically claim that their technologies will perform their function within existing, imperfect infrastructures.

Such concerns came from an invitation to stakeholders to draw connections between the promise of AVs and the real world of transport. This discussion quickly expanded outwards. Conversations about AVs propagated until they encountered a range of wider issues: sustainability, energy use and air quality; law and order (will AVs prevent or enable particular crimes?); equity and access (who will be empowered and who will be shut out?); urban form and land use (will road space expand or contract? Will new towns 
be designed around AVs as they were around cars?); health and wellbeing (will we become less physically active?).

Many workshop participants drew attention to high-order economic ramifications. There were questions relating to economic benefits from innovation but also rapid disruption of transport and adjacent sectors, including energy, insurance, maintenance and construction. The future of work, with thousands of driving jobs at risk from automation, has so far been an easy way to articulate such concerns. Several authors have highlighted the need to further assess the broad impact AVs might have on the economy ((DiClemente et al., 2014; International Transport Forum, 2015).

These contingencies, including the tension between freeing up parking space (Begg, 2014) and increasing urban sprawl (Anderson et al., 2014a, Fox, 2016), have received some early discussion in the literature. Begg (2014) provides a strong case for public bodies to help steer technology, concluding that 'automated vehicles have great potential. But we must not allow them to shape our cities in the way the internal combustion engine was allowed to in the last century... It will not be good for the economy or the environment if automated vehicles lead to lower density cities or higher car use.' (Begg, 2014). The need for regulatory action is further justified by the possibility of AVs exacerbating inequalities (Enoch, 2015; Bierstedt et al., 2014; Frisoni et al., 2016; Thomopoulos and Givoni, 2015).

It is clear that the uptake of AVs in the UK and elsewhere could have a range of societal impacts in the medium and long-term and public authorities and other governing bodies have a responsibility to anticipate and respond to these issues.

\section{Public sector's role}

The classic tension between regulation and free markets will hold with AVs as with other services/commodities but with some intriguing twists: if the technology is led by the private sector, which seems extremely likely, what will citizens and organisations expect of the public sector? Important characteristics of the AV 'experience' (e.g. speed, accessibility) will be in large part determined by regulation but will stakeholders expect government to adopt a particular principle, such as the minimisation of harm, or the maximisation of benefit, in determining how it regulates the technology?

Stakeholders, including those from the private sector, saw a significant role for governments at all levels (supranational, national, regional and local) and were in general keen to see active rather than reactive governance. This applied to both principles of governance (what should the public sector seek to achieve in the context of AVs?) and its practicality (will new governance mechanisms be necessary to respond to the aspects of AVs that set them apart from the vehicles of today?). It was notable, for example, that a representative from one transport company, who might benefit from $\mathrm{AV}$ innovation and conventionally be expected to regard top-down regulation with suspicion, concluded during one discussion that,

'I could very easily see a situation in which we get the regulatory framework for AVs wrong, that we're too laissez-faire, too deregulatory about it and effectively that the vulnerable parties that you're talking about, the older, non-tech savvy people are 
unable to access the benefits and that the 16 to 25 demographic is priced out of being able to access it and it in effect becomes a luxury urban transport.'

A laissez-faire approach to governance was strongly rejected by almost all of the stakeholders to whom we spoke. Not only would such an approach fail to realise the potential of these technologies. It would also force governments to respond, at great cost and in relative ignorance, to demands from entrenched and powerful technological constituencies for upgrades to infrastructure.

The question of balancing competing desires and needs that has dominated transport discussions around previous technologies will not evaporate. How will these be balanced as AVs grow as a proportion of the fleet? Should governments continue to allow cars to be driven manually if they are demonstrably less safe? If road safety is seen as paramount, should some road systems be cleared of other users, as they were when cars replaced horses in the early $20^{\text {th }}$ Century?

The range of uncertainties linked to AVs adoption has prompted several authors to call for further assessment of their potential impact before legislation (Anderson et al., 2014a; Fagnant et al., 2015). However, as we have discussed, these impacts will be impossible to predict in advance. There is a risk that, in waiting for risks and benefits to become clear, the technology's narrative of inevitability becomes a self-fulfilling prophecy. Governance must therefore happen under conditions of profound uncertainty. Uncertainty has always been a feature of transport planning, but new technologies and the expectations around them have the potential to further disrupt this process.

The emerging literature on self-driving cars has already surfaced some of the issues we have identified in this paper. However, these dots are often unjoined and the emphasis has been on questions and concerns that can be framed in engineering terms, such as those to do with user interaction (including handover between computer and human (Merat et al., 2012)). AVs' broader societal implications have been given much less attention, in part because of the scale of systemic uncertainty. The contribution of our stakeholder engagement has been to draw often surprising links between these issues, connecting, for example, discussions of technological risk with those of equity, land use or sustainability. (Some early technology assessment work has drawn attention to the multidimensional character of the risks surrounding AVs (Grunwald 2016)).

However, it was notable how our workshop discussions that began by focussing on new technology, its benefits, risks and public acceptability, quickly spiralled out to take in wider concerns. Our argument in this paper has been that this process of expansion must be taken seriously by those seeking to construct governance frameworks. If public and stakeholder concerns about self-driving cars are imagined as merely ones of risk and benefit, this will misrepresent the nature of public trust and make it harder to realise the public value of this technology.

The range of governance questions that could emerge as salient is vast. For example, what type of AV infrastructure should be supported and by whom? Should public authorities be responsible for investing in new infrastructure? How should drivers' training be changed - either to keep drivers engaged or adapt driving skills to AVs? Who should own and control data generated by AVs? What ownership models should be 
supported for public mobility, socioeconomic opportunities and environmental benefit? Will the predicted loss of jobs be compensated by the creation of employment and, if not, how can this be mitigated? Will the mass use of AVs contribute to decreased physical activity? Such questions, typically blending the technical with the political, are conventionally asked in hindsight. We have seen in the case of the $20^{\text {th }}$ century automobile that such an approach is unwise.

\section{Reflections on process}

As we look back on this project, we feel vindicated in our choice of workshop design and have in fact reused the "scene" concept in a workshop that had the broader focus of the $4^{\text {th }}$ industrial revolution. In addition, one of our recommendations from the project was that workshops of this type should be run amongst officials on an ongoing basis as a practical way of tackling possible technological determinism. Having said this, we realise that no deliberative process can be neutral. It would be valuable to run an experiment in which differing representations of AV dilemmas were used with comparable audiences in order to learn how much the nature of stimulus material appeared to guide conversation and any conclusions.

Our work took place in a policy context whose assumptions were at times unclear or conflicted. As independent researchers we were able to explore questions that the client organisation may have found hard to ask. That said, it became clear that a sceptical stance on AVs did not fit the corporate message. Our report's conclusions have subsequently been massaged to make them more congruent with the general narrative that AV technology is a good thing and an opportunity to be grasped.

Were we asked to carry out the project again, we might seek to render more explicit the policy context in the client organisation as a way of flushing out tensions between our presentation of the issues and what was desired or expected amongst officials. Had this been a conventional research project funded by a third party and involving government more tangentially, it is easy to imagine that there would have been none of the difficulties we encountered: officials would have noted our provocative stance but would not have felt the same to engage with it. Given that our report was going to be published by the DfT, the government was deeply invested in the work. On the negative side, this led to the difficulties that have been described; on the positive, it has meant that this research project seems to have had a good deal more policy impact than it might otherwise have had. For example, the client organisation held a symposium on social and behavioural questions relating to AVs in September 2017, at which our work was summarised by an official.

\section{Conclusion - Systemic governance}

The debate on AVs has so far been allowed to be dominated by the possibilities of technology. The scale of investment and speed of technological change have reinforced a narrative of inevitability (Alessandrini et al, 2015; Kyriakidis et al, 2015; KPMG and Center for Automotive Research). This narrative sees the role of government as risk mitigation, infrastructure adaptation and maintenance of public trust. In running a series of workshops with stakeholders in which we asked them to open this debate up, we were surprised at the speed and breadth of expansion. New questions, concerns and issues were added and debated rapidly and articulately. This suggests that any approach to 
governance that starts with technologically determinist assumptions is likely to quickly encounter trouble.

The public justification for self-driving cars shares many features of the salvationist and competitive rhetoric of previous emerging technologies, but with the volume turned up. Here is a technology, it is claimed, that will offer vast social and economic benefits while saving thousands of lives. US highways safety administrator Mark Rosekind argued that we 'cannot wait for perfect... We should be desperate for anything we can find to save people's lives' (Stoll, 2016). Alain Kornhauser, a prominent engineer said, 'If anybody legislates against it, they should probably go to jail'(Cichowski, 2017). Gary Peters, the US junior Senator from Michigan, said 'Speed is of the essence here... We're in a very important race against Asian and European countries that are moving forward with this technology' (Naughton, 2017). ${ }^{6}$

In the face of technological hubris, it is hard but vital for governments to assert themselves. Good governance for AVs should not be allowed to take the form of a race. The future in which AVs play a part will be determined as much by governments as by car companies. As Thomopoulos and Givoni (2015, p9) have commented, 'Whether the AV locks us further in or out of the 'car based society' depends on the choices we make as a society, not solely on a specific technological development'. It is therefore vital that they articulate, at an early stage, coherent visions of desirable future transport and put AVs in their place. Disruptive and utopian claims should be met with organised, incremental policies (Woodhouse and Collingridge 1993). A recent report from the House of Lords Science and Technology committee (2016) highlights the need for the UK Government to 'play a coordinating role' involving public authorities, academia and industry to 'ensure maximum economic and social benefits', but there is little guidance offered on what this role should entail.

To return to the dilemma identified by Collingridge (1980) in his study of the emergence of the motorcar, articulating visions means recognising the contingencies of unpredictable self-driving futures, a few of which have been illuminated by the stakeholders with whom we engaged. Rather than conventional risk-based regulation, engaging constructively with uncertain futures might demand a new model of 'experimental government'.

For governments to make the most of testing that is already taking place on public roads, they should assert themselves in experiments. Good governance should mean broadening the experimental protocols beyond those desired by companies. If experimentation is a form of organized question-asking, then the questions outlined in this paper should also inform AV progress. There will remain a tendency to reduce such questions to those amenable to engineering. As we have discussed in this paper, there will be dilemmas and complexities that will remain irreducible. Social foibles and value disputes cannot be fixed by algorithmic tweaks.

6 There is a resonance here with the debate on agricultural biotechnology, in which proponents of the technology accused those asking governance questions of crimes against humanity (e.g. Potrykus 2001) 
In practice, a focus on incremental, experimental government, informed by the broad range of questions in this paper might focus on matters such as standard-setting, datasharing and the articulation of clear social problems amenable to AV-based approaches. There will remain a place for open deliberation, but the challenge will be to connect its insights to governing the ongoing experiment of self-driving. Experimental rules are already being developed in some places: California demands that all AV companies provide 'disengagement reports' on incidents when technological failure prompts human involvement; meanwhile Germany has opened up certain roads for testing in exchange for assurances that manufacturers will install 'black boxes' for crash data collection. Governments should learn from examples such as agricultural biotechnology (cf Poortinga and Pidgeon 2004) to anticipate controversies over labeling (should AVs and other vehicles be compelled to reveal their mode of control?) and co-existence (how can AVs and older technologies operate alongside one another?) Such priorities are unlikely to be shared in the short term by many developers of self-driving cars, but European traditions of public transport here offer an advantage rather than a constraint. As AV innovation and investment continues, there is a clear need for the active involvement of governance bodies, informed by critical social science research.

\section{References}

Alessandrini A, Campagna A, Site P D, Filippi F, and Persia L. (2015). Automated vehicles and the rethinking of mobility and cities. In: Transportation Research Procedia. : Elsevier, pp.145-160

Anderson, J. M.; Kalra, N.; Stanley, K. D.; Sorensen, P.; Samaras, C. and Oluwatola, O. A. (2014a) Autonomous Vehicle Technology. A Guide for Policymakers. RAND Corporation. Available at: http://www.rand.org/content/dam/rand/pubs/research reports/RR400/RR4432/RAND RR443-2.pdf [Accessed 1st November 2016].

Bagwell, P. (2002). The transport revolution 1770-1985. Routledge.

Beck, U. (1995). Ecological Politics in an Age of Risk. Polity Press, Cambridge

Berman, E. P. (2013). Not Just Neoliberalism: Economization in US Science and Technology Policy. Science, Technology and Human Values, 0162243913509123.

Bertoncello, M. and Wee, D. (2015) Ten ways autonomous driving could redefine the automotive world. McKinsey. Available at:

http://www.mckinsey.com/industries/automotive-and-assembly/ourinsights/ten-ways-autonomous-driving-could-redefine-the-automotive-world [Accessed 3rd November 2016]

Bierstedt, J., Gooze, A., Gray, C., Peterman, J., Raykin, L., and Walters, J. (2014). Effects of next-generation vehicles on travel demand and highway capacity. FP Think Working Group, 10-11.

Brown M, Avery P, and Sturgeon P. (2014). Enhanced work zone safety through cooperative autonomous vehicle systems. In: 3rd International Conference on Connected Vehicles and Expo, ICCVE 2014. : Institute of Electrical and Electronics Engineers Inc., pp.966-967.

Buchanan, Colin. (1963). Traffic in towns. The Buchanan Report. London: HMSO. 1963. 
Callon, M. (1998). An essay on framing and overflowing: economic externalities revisited by sociology. The Sociological Review, 46(S1), 244-269.

Cichowski J (2017). Safety group urges states not to rush on self-driving car regulations. NorthJersey.com. 7 February. Available at:

http://www.northjersey.com/story/news/columnists/johncichowski/2017/02/07/road-warrior-dont-rush-into-self-drivingregs/97402044/ (accessed 12 March 2017)

Clark, Ben, Parkhurst, Graham, and Ricci, Miriam. (2016). The potential impact of autonomous vehicles on transport systems and society: a review and future prospects. In: Universities' Transport Study Group. Bristol: pp.1-12.

Cohen, T, Jones, P and Cavoli, C (2017) Social and behavioural questions associated with automated vehicles Scoping study by UCL Transport Institute, Final report, https://www.gov.uk/government/uploads/system/uploads/attachment data/file 585545/social-and-behavioural-questions-associated-with-automated-vehiclesfinal-report.pdf

Collingridge, D, (1980), The Social Control of Technology, Open University Press

Colwell R. (2015). Our computer systems are not good enough. In: 4th Berkeley Symposium on Energy Efficient Electronic Systems, E3S 2015. : Institute of Electrical and Electronics Engineers Inc.

Council for Science and Technology (2015) Capturing value in the autonomous and connected vehicles industry: an ambitious plan for the UK, letter to the Prime Minister, 23 July 2015, available at https://www.gov.uk/government/uploads/system/uploads/attachment data/file /459521/cst-15-1-driverless-vehicles.pdf, accessed 11 May 2017

DiClemente Jonathan, Mogos Serban, and Wang Ruby. (2014). Autonomous Car Policy Report. Pittsburgh: Carnegie Mellon University .

Enoch M P. (2015). How a rapid modal convergence into a universal automated taxi service could be the future for local passenger transport. Technology Analysis and Strategic Management, 27(8), pp.910-924.

Fagnant Daniel J, and Kockelman Kara M. (2013). Preparing a nation for autonomous vehicles. Transportation Research Part A journal, 77(October), pp.1-32.

Felix R, Economou J, and Knowles K. (2015). Driverless Vehicles and LIDAR: Evaluation of Possible Security Threats on the Open Road. SAE Technical Papers, 2015April(April)

Feng J, Li X, Pasiliao E L, Jr , and Shea J M. (2014). Jammer placement to partition wireless network. In: 2014 IEEE Globecom Workshops, GC Wkshps 2014. : Institute of Electrical and Electronics Engineers Inc., pp.1487-1492.

Fisher, Erik, Roop L. Mahajan, and Carl Mitcham. 'Midstream modulation of technology: governance from within.' Bulletin of Science, Technology and Society 26, no. 6 (2006): 485-496.

Fisher, E. (2015) Socio-technical integration research, presentation at the University of Sussex, 2015

Fox, Sarah. (2016). Planning for Density in a Driverless World. SSRN Electronic Journal, 20001(202)

Roberta Frisoni, Andrea Dall'Oglio, Craig Nelson, James Long, Christoph Vollath, Davide Ranghetti, and Sarah McMinimy. (2013). Self-Piloted Cars: the future of road transport? Available at:

http://www.europarl.europa.eu/thinktank/en/document.html?reference=IPOL ST $\underline{\mathrm{U}(2016) 573434}$. 
Godin, B. (2006). The linear model of innovation: The historical construction of an analytical framework. Science, Technology, and Human Values, 31(6), 639-667.

Grove-White, Robin, Phil Macnaghten, and Brian Wynne. 'Wising up: the public and new technologies.' Lancaster: IEPPP, Lancaster University (2000).

Groves, C. (2015). Logic of choice or logic of care? Uncertainty, technological mediation and responsible innovation. NanoEthics, 9(3), 321-333.

Grunwald, A. (2016). Societal Risk Constellations for Autonomous Driving. Analysis, Historical Context and Assessment. In Autonomous Driving (pp. 641-663). Springer Berlin Heidelberg.

Guerra E. (2015). When autonomous cars take to the road. Planning, 81(5), pp.36-38.

Guston, David H. (2014). 'Understanding 'Anticipatory Governance'.' Social Studies of Science 44 (2):218-242.

Guston, David H., and Daniel Sarewitz. (2002) 'Real-time technology assessment.' Technology in society 24, no. 1 (2002): 93-109.

House of Lords (2017). Connected and Autonomous Vehicles: The future?. Science and Technology Select Committee, 2nd Report of Session 2016-17 https://www.publications.parliament.uk/pa/ld201617/ldselect/ldsctech/115/11 5.pdfHughes, Thomas Parke. (1993) Networks of power: electrification in Western society, 1880-1930. JHU Press, 1993.

International Transport Forum, and OECD . (2015). Urban Mobility System Upgrade Urban Mobility System Upgrade. Oecd, , pp.34-34.

Irwin, A. (2016). On the local constitution of global futures. Science and democratic engagement in a decentred world. Nordic Journal of Science and Technology Studies, 3(2), 24-33.

Jasanoff, Sheila. (2003) 'Technologies of humility: citizen participation in governing science.' Minerva 41, no. 3 (2003): 223-244.

Kearnes, Matthew, Robin Grove-White, Phil Macnaghten, James Wilsdon, and Brian Wynne. (2006) 'From bio to nano: learning lessons from the UK agricultural biotechnology controversy.' Science as culture 15, no. 4 (2006): 291-307.

KPMG and Center for Automotive Research. (2012). Self-driving cars : The next revolution.

KPMG (2015). Automobile insurance in the era of autonomous vehicles.

Kröger, Fabian. (2016) 'Automated Driving in Its Social, Historical and Cultural Contexts.' In Autonomous Driving, pp. 41-68. Springer Berlin Heidelberg, 2016.

Kyriakidis M, Happee R, De Winter , and J C F. (2015). Public opinion on automated driving: Results of an international questionnaire among 5000 respondents. Transportation Research Part F: Traffic Psychology and Behaviour, 32, pp.127-140.

Le Vine, Scott, and Polak, John. (2014). Automated Cars : A smooth ride ahead?

Martens, K. (2016). Transport justice: Designing fair transportation systems. Routledge.

McTiernan, K., Polagye, B., Fisher, E., \& Jenkins June, L. (2016). Integrating sociotechnical research with future visions for tidal energy.

Merat N, Jamson A H, Lai F C.H, and Carsten O. (2012). Highly automated driving, secondary task performance, and driver state. Human Factors, 54(5), pp.762-771.

Miller, T and Neff, M (2013) De-Facto Science Policy in the Making: How Scientists Shape Science Policy and Why it Matters (or, Why STS and STP Scholars Should Socialize), Minerva (2013) 51:295-315

Mindell, D. A. (2015). Our robots, ourselves: Robotics and the myths of autonomy. Viking Adult. 
Morgan, P., Alford, C. and Parkhurst, G. (2016) Handover issues in autonomous driving: A literature review. Project Report. University of the West of England, Bristol, UK. Available from: http://eprints.uwe.ac.uk/29167

Naughton K (2017). Robot cars to descend on 10 sites U.S. names as proving grounds. Bloomberg. 19 January. Available at:

https://www.bloomberg.com/news/articles/2017-01-20/robot-cars-to- descendon-10-sites-u-s-names-as-proving-grounds (accessed 12 March 2017)

Nordmann, A. (2014). Responsible innovation, the art and craft of anticipation. Journal of Responsible Innovation, 1(1), 87-98.

Nye, David E. (2007) Technology matters: Questions to live with. MIT Press, 2007.

Pellizzoni, L. (2004). Responsibility and environmental governance. Environmental politics, 13(3), 541-565.:

Poortinga, W., and Pidgeon, N. (2004). Public Perceptions of Genetically Modified Food and Crops, and the GM Nation? Public Debate on the Commercialisation of Agricultural Biotechnology in The UK: Main Findings of a British Survey. Centre for Environmental Risk. Understanding Risk Working Paper 04-01

Potrykus, I. (2001). The 'golden rice' tale. In Vitro Cellular and Developmental BiologyPlant, 37(2), 93-100.

Ravetz, J. R. (1997). The science of 'what-if?'. Futures, 29(6), 533-539.

Richardson, H. S. (1999). Institutionally divided moral responsibility. Social Philosophy and Policy, 16(02), 218-249.

Rip, Arie. 2006. 'A Co-Evolutionary Approach to Reflexive Governance-and its Ironies.' In Reflexive Governance for Sustainable Development, ed. Jan-Peter Voss and Dierk Bauknecht, 82-100. Cheltenham: Edward Elgar Publishing

Stayton, E (2015) Driverless Dreams; Technological Narratives and the Shape of the Automated Car, MSc Thesis, MIT

Stilgoe, J. (2018) Machine learning and social learning, Social Studies of Science, 48 (1) pp. $25-56$

Stilgoe, J., Owen, R., and Macnaghten, P. (2013). Developing a framework for responsible innovation. Research Policy, 42(9), 1568-1580

Stoll J (2016). Tesla Autopilot crash shouldn't slow self-driving development, regulator says. The Wall Street Journal. 22 July. Available at http://www.wsj.com/articles/tesla-autopilot-crash-shouldnt-slow-self-drivingdevelopment-regulator-says-1469200956 (accessed 12 March 2017)

Szerszynski, Bronislaw, Matthew Kearnes, Phil Macnaghten, Richard Owen, and Jack Stilgoe. 'Why solar radiation management geoengineering and democracy won't mix.' Environment and Planning A 45, no. 12 (2013): 2809-2816.

Thomopoulos Nikolas, and Givoni Moshe. (2015). The autonomous car--a blessing or a curse for the future of low carbon mobility? An exploration of likely vs. desirable outcomes. European Journal of Futures Research, 3(1), pp.1-14.

Ticoll David. (2015). Driving Changes: Automated Vehicles in Toronto (Discussion Paper). Toronto: , pp.67-67. Available at:

https://www.researchgate.net/publication/287829194 Driving Changes Automat ed Vehicles in Toronto.

von Schomberg, René. 2013. 'A Vision of Responsible Innovation' In Responsible Innovation: Managing the Responsible Emergence of Science and Innovation in Society, ed. Richard Owen, John Bessant, and Maggy Heintz, 27-50. Hoboken, NJ: John Wiley and Sons. 
Urry, J. (1999). Automobility, Car Culture and Weightless Travel: A discussion paper http://www.lancs.ac.uk/fass/sociology/research/publications/papers/urryautomobility.pdf

Wetmore, J. (2003). Driving the dream. The history and motivations behind 60 years of automated highway systems in America. Automotive History Review, 7, 4-19.

Williams, L., Macnaghten, P., Davies, R., and Curtis, S. (2015). Framing 'fracking': Exploring public perceptions of hydraulic fracturing in the United Kingdom. Public Understanding of Science, 0963662515595159.

Wolmar Christian. (2016). Transport's favourite myth. New Statesman, 145(5309), pp.18-19.

Woodhouse, E. J., and Collingridge, D. (1993). Incrementalism, intelligent trial-and-error, and the future of political decision theory. In Redner, H. (ed) (1993). An heretical heir of the enlightenment: Politics, policy, and science in the work of Charles E. Lindblom. Westview Pr.

Woodhouse, E. J., and Collingridge, D. (1993). Incrementalism, intelligent trial-and-error, and the future of political decision theory. In Redner, H. (ed) (1993). An heretical heir of the enlightenment: Politics, policy, and science in the work of Charles E. Lindblom. Westview Pr.

Wynne, Brian. 2002. 'Risk and Environment as Legitimatory Discourses of Technology: Reflexivity Inside Out?' Current Sociology 50 (3):459-477. 


\section{Appendix 1: Scene summaries}

\section{A: A clash of ideas}

Controversy surrounds a brewery's offer of a free (autonomous) ride home for any customer spending more than $£ 30$ in one of its pubs. Various public health organisations object on the grounds that this will increase problem drinking; the brewery responds that, in rural areas, pubs often provide the only social outlet but have been closing as drink-driving enforcement has increased. The autonomous ride is nothing new, it argues, since pubs are all doing deals with taxi firms.

\section{B: Of youth and age}

The National Pensioners' Foundation produces evidence showing that widespread adoption of driverless car technologies would prevent social isolation in older people and calls for the government to subsidise rides in the new driverless Urban Transit cars for the elderly. This elicits a mixed response.

\section{C: What's my job worth?}

A delivery driver's frustration at how tedious his working life has become strikes a chord with other listeners of a local radio phone-in. He complains that he spends half his life sitting doing nothing between drops and fears that, once a robot can knock on doors, he'll be out of a job for good. Other listeners express sympathy - 'it's not really a job is it?'

\section{D: Zero day}

A recent release of firmware on a line of AVs has been found to be vulnerable after hackers disseminate compromising information concerning the location of a prominent celebrity's vehicle, fuelling speculation about her love life. The celebrity is suing the manufacturer for invasion of privacy. The manufacturer is currently saying no more than that it takes breaches of its customers' privacy very seriously and that it is investigating.

\section{E: It should never have happened}

Thirteen-year old Peter Leicester was knocked down by an autonomous vehicle (operating in full self-driving mode) in Surbiton, south London. It is suggested that Peter and his friends had been playing 'chicken', forcing vehicles to make emergency stops. This is the first UK case of hospitalisation following a collision involving an AV and Peter's condition is stable. The police are investigating and are in touch with the vehicle's manufacturer.

\section{F: Trunk road conversion}

The Planning Inspectorate is hearing an application under the Town and Country Planning Act for a section of the A3 to be converted to exclusive used by AVs conforming to IS093241. The promoter wishes to enable $180 \mathrm{~km} / \mathrm{h}$ operation on the segregated road, implying $2 \mathrm{~m}$ barriers, conversion of major junctions to 'gated' status, closure of minor junctions etc. Today: oral representations from Surrey County Council, Guildford Borough Council and Dream Vehicles (whose 'family vans' are designed in accordance with IS093226).

\section{G: Automated mugging}


Criminals have been taking advantage of AVs' programming to carry out car-jackings and muggings. They surround vehicles which automatically stop, then smash windows, threaten occupants etc. Passengers have complained that the humiliation of being robbed is compounded when the vehicles detect damage and go into a 'complete stop' mode.

Following a series of high-profile incidents in wealthy, low-density areas at night, the Transport Select Committee has announced an inquiry on personal security and autonomous vehicles.

\section{H: Commuters welcome the 25+ hour day}

Car-commuters who have converted to AV are reporting significant benefits from the change. They arrive at their destination less tired and stressed and are using the journey time productively, be that in carrying out personal admin, spending more 'virtual' time with their families, or getting on with their work. Certain companies are responding to the last of these by counting AV travel time as part of the working day (if evidence of labour is provided).

\section{I: Mayor 'robustly confronted'}

In response to the predicted increase in $\mathrm{AV}$ use, largely as taxis, Borchester Borough Council has removed most of its off-street parking. This provokes a strong reaction from the Borchester AV Owners Society whose objections include retailer concerns about losing trade from visitors and rural residents and harm to the vehicle manufacturing industry. In addition, pedestrian/ cycling groups do not welcome a predicted increase in overall traffic.

\section{J: Emergency meeting called by minister}

The Daily Mail, through an FOI request, has learnt that cities pioneering AVs have seen a rise in delays to emergency vehicles, resulting from vehicles behaving inconsistently in response to the approach of ambulances etc.

The minister has announced legislation to ensure that all AVs sold in the UK are to have compatible vehicle emergency recognition and avoidance strategies. Vehicle manufacturers are expected to argue as to which maker's standards are the ones to be universally adopted.

\section{K: Ethical dilemmas}

The behavioural algorithm for vehicles conforming to IS094622 was based on the recommendations of a committee of eminent moral philosophers. The algorithm, when forced to choose between two individuals, prefers the younger, ceteris paribus. But, in a recent incident, a car prioritised a four-year old boy with a degenerative condition over a 78-year-old grandmother of 13.

The chair of the committee has been the target of death threats etc and various antitechnology groups are renewing their campaigns for the standard to be revoked.

\section{L: System failure}

A former technophile is locked for two days in a remote location inside his fully automated vehicle when it has a complete system failure. He responds by launching a campaign for manual override to be mandatory in all AVs and for all road vehicles in motion to contain at least one individual competent to drive. 


\section{Appendix 2: Questions emerging from workshop}

Source
Mapping
Mapping
Mapping
Mapping
Scenes
Scenes
Scenes
Literature review
Expert interview
Expert interview
Mapping
Mapping

Mapping

Other

Literature review

Mapping

Mapping

Mapping

Mapping

Mapping

Expert interview

Expert interview

Literature review

Mapping

Mapping

Mapping

\section{Question}

How does data openness (and its opposite) affect a) what is possible, b) how technology might develop and c) what response it might elicit?

How large a role will the insurance industry have in determining what technology emerges when (by deciding which risks it is prepared to insure and at what price)?

Can vehicle manufacturers be relied upon to adopt voluntary codes such as NCAP?

How will competition between traditional OEMs and Google/Apple affect the AV development process?

What would development in a largely unregulated market look like? Who will own the data?

Is there a business case for platooning (freight vehicles)?

What is/are the benefit-cost ratio(s) of the introduction of AVs?

What would be the true benefits (if any) of mixed fleet operation?

What is AVs' commercial proposition?

How will software update fit with individuals' travel schedules?

What about a fundamental system failure such as loss of GNSS following a solar flare?

Since software updates take time, will vehicles be unavoidably 'out of service' at inconvenient times?

Might emergency override be limited to enabling the occupant(s) to leave the vehicle?

If all software has bugs, what is the worst-case scenario for failure and how 'safe' is the failsafe?

Will (and, if so, when will) AVs be an affordable option for more than the hyper-rich?

Would a market-led development process be bound to exclude certain user groups?

Will the technology be developed with disabled people in mind?

Will there be, in effect, different 'classes' of AV travel?

How can technology be made accessible to (nearly) all?

What will be the user interface (for requesting a trip, say) and will it be designed inclusively?

What can increased (as opposed to full) automation do for those with (all types of) mobility impairments?

Will elder persons, disabled and non-drivers, such as underage children, have the capacity to use these vehicles?

What if demand for AV mobility cannot be accommodated within the existing highway footprint?

How compatible is current infrastructure with the requirements of AVs?

What communication infrastructure is required to enable AVs to operate and how disruptive and costly would its implementation be? 
Mapping

Mapping

Scenes

Expert interview

Expert interview

Literature review

Literature review

Literature review

Mapping

Mapping

Mapping

Scenes

Scenes

Scenes

Literature review

Other

Other

Expert interview

Mapping

Mapping

Mapping

Mapping

Mapping
Would communication infrastructure be 'future proofed'?

Who would pay for the on-road communication infrastructure?

Will infrastructure supporting AV operation develop at the same rate as the AVs themselves?

What will happen to 'the ride' with increasing autonomy - heave, jerk, bumps etc? Is a change in the condition of the highway network likely/affordable/desirable?

What environments are best suited to the operation of AVs and why (eg campuses, places with very low parking provision)?

Do AVs require large scale infrastructure to function safely and effectively?

What infrastructure is required to support different type of AVs and roll-out scenarios (e.g. connected or non-connected AVs, urban or rural set up, type of vehicle, segregated lanes, etc.)

Who should pay for the new infrastructure?

What will be the impacts on privacy, security and responsibility during a transitional phrase (ie before any technology is 'proven')? How might technology respond to differences of environment? (eg if it takes 18 months to adapt a left-hand drive system to a right-hand drive environment)

What is the relationship between advances in $\mathrm{AI}$ and $\mathrm{AV}$ development? (Will the first wave of fully automated vehicles be only 'quite' clever?)

Can an incremental transition towards automation co-exist with a direct step to automation? How would this play out in the market? What if the technology halts short of full automation? Supposing driver-support systems will continue to feature at first on the most expensive vehicles, what is the likely cascade pattern?

If full automation is the 'destination', what is the optimal pathway to it?

Will retrofitting (introducing technology into 'conventional' vehicles') increase the speed of AV deployment?

Will teething troubles mean that things get worse before they get better?

What are the potential timelines for the development and adoption of technological developments?

Will those who insist on data privacy/anonymity be excluded or is there an AV-light for them?

Could there be a range of control in a fully automated fleet? (ie some vehicles are more autonomous than others.)

How might AV technology preserve 'the driving experience' for those who want it?

Can increasing automation cater to a multiplicity of cultures and visions? (eg if City A wants high-tech and City B wants a focus on arts and culture)

If manual driving remains possible when the bulk of vehicles are fully automated, how would this work in traffic management terms and would the driver be expected to pay for the privilege (and the safety cost they impose)? 
Mapping If manual vehicles remain the dominant form, what role will fully

Mapping

Mapping

Mapping

Literature review

Mapping

Mapping

Mapping

Mapping

Mapping

Mapping

Mapping

Mapping

Mapping

Mapping

Scenes

Scenes

Scenes

Scenes

Other

Expert interview

Expert interview automated vehicles play and where will they be used?

Might problems of a mixed fleet put an end to automation?

Would differential insurance rates enable a mixed fleet to work?

How best to respond to the desire to retain the joy of driving?

Is 'old technology' bound to be edged out in time? Will it be edged out by being made difficult to use?

In a highly (but not fully) automated car, does the need to be able to respond at short notice in an emergency imply a different skillset for the driver than hitherto?

How might AVs 'learn' of incidents such as temporary closures and how would this answer differ depending on the level of a vehicle's connectedness?

How much will efficiency determine the dominant technology and regime?

Will a person inside an AV have exactly the same value as a person outside an AV?

What does the notion of machine learning imply for compliance with regulations (eg will cars through learning develop new approaches that go beyond what is set out in regulations)?

If an AV learns a useful lesson (about interpreting particular visual information, say), how widely and by what means would this knowledge spread?

How 'smooth' can the ride in an AV become?

Will there be a hierarchy of journey types and, if so, how will that hierarchy operate?

If the fleet delivers sufficient capacity to meet peak demand, does this mean that there will be significant unused capacity at other times? Where will the vehicles go?

Might there be large AVs that provide extra space for those that want and can afford it?

If AVs operate as taxis, how will this play out in terms of needing to deliver in the centre and collect from the centre but (presumably) be somewhere other than the centre during the day?

Could vehicles be designed to carry people some of the time and freight the rest of the time?

What will be the drive train of AVs and, if it's electricity, how will that be serviced?

If people no longer need to buy a vehicle that satisfies peak demand (eg a holiday trip involving all family members and their possessions), what does this imply for the future size distribution of the fleet?

Should AVs be differentiable from manual vehicles?

Will there be three distinct types of vehicle - for one-off trips, for commuting, and for long-distance (ie motorway)?

What would full automation mean for the design and form of vehicles? 
Expert interview In the absence of driver gesture, how should (fully automated) AVs communicate with other road users?

Literature review To what extent AVs have the potential to be low emission vehicles?

Mapping What is true willingness to pay for automation a) as an additional feature of an owned vehicle, b) as a characteristic of a journey?

Mapping

Mapping

Mapping

Mapping

Mapping

Mapping

Mapping

Mapping

Mapping

How will international variations in infrastructure (extent and quality) influence use of AVs?

How might the perceived benefits/costs of AVs affect the balance of business/personal a) vehicle ownership and b) use?

What will using AVs cost?

What benefits will people expect to receive in order to be prepared to surrender personal information?

What benefits will people expect to receive in order to accept the risk that their personal information may be misused in some way?

If those who find driving annoying or unpleasant are the 'near market' for AVs, how many are there and how near are they?

How will international variations in culture influence use of AVs?

If it becomes possible to 'convert' a manual car to full automation, what would be the results?

Scenes

Might AVs be adopted at different rates in urban, peri-urban, rural areas?

What is the role of premium marques (Rolls Royce etc) in an AV world?

Scenes

Scenes

How alluring will AVs be?

Scenes

Scenes

Scenes

Literature review

Is the probably limited space within an AV (in contrast with a train, say) likely to limit enthusiasm for this form of travel?

Will those who enjoy the sense of control they derive from driving be prepared to give it up?

Will those who choose to own vehicles prefer to own manual vehicles and, if so, for how long?

How will international variations in wealth influence use of AVs?

Would the attraction of AVs diminish as they became more widely available? (eg if the efficiency benefits experienced by early adopters were not matched once the roads were full of AVs)

Expert interview What happens to consumer enthusiasm between being told of the concept and experiencing the technology?

Literature review What will the cost of AV travel be according to the different 'roll-out scenarios'

Literature review How will AVs interact with other road users, in particular car drivers, pedestrians and cyclists, under different 'use scenarios', including in urban areas?

Literature review Could AVs interact with other road users lead to unsafe situations?

Literature review Could AVs interact with other road users negatively affect traffic flow?

Literature review Under what conditions to allow AV users to engage in non-driving tasks in partially or highly automated vehicles?

Literature review What solutions, such as training, should be implemented to keep the 
Literature review

Literature review

Literature review

Scenes

Scenes

Scenes

Scenes

Literature review

Other

Literature review

Literature review

Literature review

Expert interview

Literature review

Literature review

Literature review

Mapping

Mapping

Mapping

Mapping

Mapping

Mapping

Mapping

Mapping

Scenes

Scenes driver engaged and maintain/adapt driving skills?

To what extent will drivers be able to/want to work whilst in AVs?

Could motion sickness issues prevent most drivers from engaging in non-driving tasks? To what extent will AVs reduce drivers' stress?

To what extent could drivers' attachment to driving can affect AV adoption?

Does the historic dichotomy between American and European car standards predict a similar situation for AVs?

Are urban areas the least well suited to fully automated vehicles?

How will AVs deal with local variations (eg different road-lining practices between municipalities)?

Will different levels of automation and/or forms of technology be naturally better suited to some spatial and highway environments than others? (eg will full automation fare better in a rural environment or on a motorway?)

Will AVs be more appropriate to some settings than others? (eg contrasting Singapore which has sought to reduce car use with other jurisdictions that have tolerated it)

Can controlled operation ever be realistic in remote areas?

What are the critical thresholds of settlement size that make different patterns of AV operation feasible/desirable?

Are AVs bound to be more successful in relatively closed highway environments such as motorways and, if so, does this imply that they will be most prevalent in such environments?

Is there scope for developing nations to 'leapfrog' countries with a highly developed infrastructure geared to manual vehicles and, if so, what would this imply?

How will developments play out in the different transport markets, eg east Asia, Africa, as well as the more developed economies?

What shape a connected and integrated automated freight and delivery system could take?

To what extent negative externalities linked to the use of AVs could lead to a market failure?

What are the opportunities and challenges of introducing AVs in nonWestern countries?

Will mass transit be/remain the poor person's choice?

Will AVs remove walk stages to and from public transport?

How would the impacts of retrofitting differ from those of 'newbuild' AVs?

Will AVs replace journeys made by active travel?

If 'peak car' is real, what do AVs mean for that phenomenon?

What might AVs do to the balance of journey purposes?

Will AVs enable 'time shifting' of journeys to take place?

Will safety gains from AVs be converted into increased speed?

Will AVs herald an increase in vehicle-km?

Will full automation lead to increased aggregate mobility (eg, instead of driving two children to a single school, the parent will despatch each to a different place of learning and make a separate trip to the gym) 
Scenes

Scenes

Scenes

Scenes

Literature review

Expert interview

Mapping

Scenes

Other

Other

Mapping

Mapping

Mapping

Mapping

Mapping

Literature review

Expert interview

Literature review

Literature review

Literature review

Literature review

Literature review

Literature review

Mapping
If the usage pattern is predominantly not based on personal vehicle ownership, how will the lack of a sunk cost affect travel behaviour? What will happen to the ratio of passenger-km to vehicle-km? How would different models of ownership/use affect a) total vehicle$\mathrm{km}$ and passenger-km, b) need for parking, c) replacement frequency, d) congestion, e) cost per unit distance, f) number of vehicles required to meet demand?

If a presumption to avoid harm meant that AVs would travel at a uselessly low speed in urban areas, what would happen?

What will be the aggregate effect on vkm?

What would happen if the sum currently devoted to concessionary fares were reallocated to subsidised AV trips?

Can routine ('planned') handback be made sufficiently safe?

Can emergency handback work?

How will the negotiation between road users (eg through eye contact) be modified by the advent of AVs?

If override is possible, will drivers who become frustrated at the timidity of their automated vehicle simply wrest back control? Does the answer depend on what the occupant is doing during the journey?

Will those who own and share AVs be able to trust other users and can this be influenced by reputational tools?

Will we ride in AVs with strangers in the future?

How many AVs will be owned and used exclusively by their owners?

Will the usage pattern (eg owned/hired) differ by location (eg urban/rural)?

Are some ownership/use models more socially desirable and, if so, which and why?

If a taxi model became prevalent, who would own the vehicles?

Will people want to use lots of different vehicle types, reflecting their different needs/aspirations? (eg 2-seater sporty number for fun, estate for holidays)

What impact different AV uptake scenarios might have on modal share, in particular on the use of public transport and walking?

To what extent public authorities should invest/support automated mobility on demand systems?

What are the practicalities of establishing shared AV systems, including forecasts of market penetration, system design, implementation and operation?

How might urban form accommodate AVs in line with different mobility/environment visions? (eg how would a prioritisation of walking and public space affect the provision of infrastructure on which AVs would operate?)

How will mass transit and individual transport interact in an AV world?

How can AVs contribute to or undermine the achievement of a given vision for an area (urban or otherwise)?

What will be the impact on software development and associated industries? 
Mapping

Mapping

Mapping

Scenes

Scenes

Scenes

Scenes

Scenes

Scenes

Other

Expert interview

Expert interview

Literature review

Literature review

Literature review

Scenes

Scenes

Other

Literature review

Literature review

Mapping

Mapping

Mapping

Mapping

Scenes
What will be the net impact upon employment?

How gradual or sudden might economic adjustments arising from AVs be?

What will be the net impact on GDP at a global, UK and UK-region level?

What will be the net combined financial impact of AVs on a) individuals, b) society, c) the national economy?

What will be the life cycle of AVs - when people replace their vehicles, who will inherit them and with what consequences? How productive will people actually be in an AV?

How productive will in-vehicle working time be?

Instead of a parking place, might accommodation in future be bundled with a 'mobility package'?

Will private-sector organisations such as retailers use AVs to bring customers to their outlets?

Would employers ascribe the same value to in-AV time as time spent in a fixed location?

What might a truly 'mobile office' mean for economic impacts such as agglomeration benefits?

Could freight reap early rewards of automation in terms of nighttime deliveries without flouting driver-hour restrictions?

How many jobs directly and indirectly related to AVs, across sectors, could be at risk?

How many jobs directly and indirectly related to AVs, across sectors, could be generated?

To what extent will mass AV market penetration will lead to desirable socioeconomic outcomes?

What will be the short- and long-term effects of AV introduction on

a) total energy use and energy consumed per vehicle-km/passenger$\mathrm{km}$ ?

What will be the net effect of AV introduction on greenhouse gas emissions?

Will AVs operate more efficiently, therefore (in the case of ICE) leading to improved air quality?

To what extent could AVs contribute to energy and emission reduction - under which use scenario?

Under which scenario could AV use lead to an increase in vehicle emission and energy consumption?

Would the 'working commute' discourage commuting by physically active modes?

What will increasing automation mean for drivers' stress levels?

Can increasing automation make driving possible at a later age than currently?

Is the last-mile model of AV use socially desirable (eg in terms of public health)?

What will AVs do to public health? 
Scenes

Scenes

Expert interview

Expert interview

Literature review

Literature review

Mapping

Mapping

Mapping

Mapping

Scenes

Literature review

Literature review

Mapping

Mapping

Scenes

Other

Literature review

Literature review

Expert interview

Literature review

Scenes

Scenes

Expert interview

Expert interview

Literature review
Might AVs reduce older people's risks of falling?

Can AVs slow the transition from independent living to residential care?

What are the potential social benefits of reversing 'circumscribed mobility' on the part of older people and others whose travel is limited under present circumstances?

What would be the net health impact (physical and mental) of increased mobility through AVs (with particular reference to older people)?

Will the mass use of AVs shift travel patterns and reduce the share of walking and cycling?

To what extent do AVs have the potential to improve the life of nondrivers, in particular the elderly and the disabled?

will corporate prosecution grow in prevalence?

What are the real risks to AV users of cyber-terrorism?

What will the implications of increased automation be for policing (eg reduced fine income but also reduced need for enforcement)?

If AVs were perceived as the plaything of the rich, would this lead to social unrest?

Whilst major organisations involved in AVs will have a global brand to protect, smaller operators may not be thus motivated. Can they be expected to behave with propriety or might 'cowboy' practices be seen?

If I own an automated car in/by which a third party is injured, what is my liability?

How might unions react in respect of industries most affected by increased automation?

What will be the true journey-time reliability impacts of AVs?

Is a reduction in congestion dependent on full automation? On high levels of control?

What will traffic density be in future and how much will this vary across the day/week/year?

What will be the aggregate area of the highway network?

What does the optimal operation of AVs mean for congestion?

If the demand for on-street parking in urban centres diminished, how would the highway space released be used?

What would be the consequences of allocating certain lanes on carriageways to AVs?

What impact will different Avs roll-out and adoption scenarios have on traffic flow in different environments (e.g. urban areas)?

How soon and with what confidence can it be known whether AVs represent a road safety improvement?

What are the unforeseen consequences with respect to road safety?

What are the plausible safety outcomes of different automation, adoption and regime scenarios?

What can the aviation sector tell us about near misses?

To what extent are manufacturers addressing driver's reengagement with the vehicle and interaction with other road users issues? To what extent should the government further support research and 
development in this field?

Mapping

Mapping

Mapping

Mapping

Mapping

Mapping

Mapping

Mapping

Mapping

Mapping

Mapping

Scenes

Literature review

Other

Expert interview

Mapping

Mapping

Mapping

Mapping

Mapping

Mapping

Scenes

Scenes

Scenes

Scenes
How will social norms change in response to the advent of AVs?

In a mixed-fleet scenario, will some of those travelling by means other than AV deliberately bait the automated vehicle?

Will people see time spent within AVs as leisure time?

If humans need to hold someone responsible, who will be responsible when automated vehicles are involved in collisions in future?

What happens in collective transport when we remove the figure of authority (driver)?

What will AVs do to the meaning of 'personal responsibility' on the part of other highway users, in the case of jaywalkers, for example? What will AVs mean for the use of alcohol and other intoxicants? What are the possible implications of full automation for people not old enough to have a conventional driving licence?

Even if developed rigorously and with the best intentions, can an algorithm that chooses person A over person B ever be acceptable? If AVs bring greater accessibility for some at the cost of increased inequality (of accessibility), what is an acceptable balance?

Will experience of near/full automation change people who drive manual vehicles?

What does a predicted blurring of private and public transport imply in terms of social attitudes?

Can society accept a computer making a life/death decision?

Is there a legitimate case for driving at an individual in 'self defence' and does the answer to this question change with increased automation?

How would citizens feel about the relative attractiveness of control and autonomy?

Will access to the highway cease being democratic (ie equally available to all whose vehicle complies)?

How will the digital divide be manifested as AVs develop? (eg wrt to elderly)

Will the 'productivity benefits' of AVs be limited to white-collar workers?

What are the distributional impacts of AVs?

What might be the overall effect of AVs on accessibility (eg increasing it for some and possibly reducing it for others)?

How do private and social benefit interact a) at the various levels of automation and market penetration, b) in urban, peri-urban, rural areas?

Will AVs lead to social fragmentation as people spend more time closeted away?

If people no longer receive a 'buzz' from driving, how else will they meet that need?

Can personal ratings be an effective way of ensuring good conduct?

What of those who are excluded by such a system?

Could a longer-term impact be availability of certain services (eg 
Scenes

Scenes

Scenes

Literature review

Expert interview

Expert interview

Expert interview

Literature review

Literature review

Mapping

Mapping

Mapping

Mapping

Mapping

Mapping

Mapping

Mapping

Mapping

Mapping

Mapping

Mapping

Mapping

Mapping

Literature review

Mapping

Mapping

Mapping

Mapping doctors' surgeries) for more hours per day?

Do AVs herald the end of peripatetic service delivery (eg district nurses), it being more efficient to 'bus' patients to a central point? Might the idea of a 'working commute' further erode boundaries between work and home?

How feasible will it be to work, read etc in an AV?

What will be the distribution of any benefits and will that distribution be acceptable?

What will increasing detachment from driving mean for drivers? What impact (if any) will AVs have upon intergenerational fairness? How might AVs be used to improve the life chances of disadvantaged people?

'To what degree should AVs prioritize minimizing injuries to their occupants, versus other crash-involved parties? And should owners be allowed to adjust such settings?' (Fagnant et al, 2015)

Will the uptake of AVs widen inequity? Or, on the contrary, will it improve accessibility for all through shared mobility?

Will AVs 'generate high-skilled jobs' (Cable) and, if so, how?

How might value of time be affected by the potential release of driving time?

How might the relative costs of other modes (eg train) be affected by AVs?

What will happen to the parking industry if fully automated vehicles are adopted largely on a taxi use model?

Will vehicles be more expensive to repair in future?

Do AVs mean fewer vehicles will be produced?

What will happen to the non-driving aspect of the professional driving role (managing luggage, helping individuals into/out of vehicles)?

What will be the impact on the professional driving sector?

What will be the impact on the insurance industry?

What will be the impact on the parking industry?

What will be the impact on the vehicle repair industry?

To what extent and in what ways will freight/logistics be affected by AVs?

Will AVs damage the business models of conventional public transport?

Does increasing automation harm the case for high-speed rail or other major public transport initiatives?

What effect will AV used in the context of shared mobility have on the insurance industry?

If moving to the city is in part a function of poor transport links in rural areas, what might AVs do for land use?

Is it conceivable that the advent of AVs will lead to an increase in highway infrastructure?

If the demand for off-street parking in urban centres diminished, what would happen to the land released and who would benefit? What are the likely effects of increased automation on land use, especially density? 
Scenes

Scenes

Scenes

Scenes

Literature review

Literature review

Literature review

Scenes

Scenes

Scenes

Scenes

Scenes

Expert interview Expert interview Mapping

Mapping

Expert interview

Scenes

Scenes

Scenes

Scenes

Scenes

Scenes

Scenes

Scenes
What might AVs mean for the design of new urban areas?

Will automated parking enable many more vehicles to fit into a typical car park?

In a world of full automation, what does a pedestrian crossing look like?

What might increasing automation mean for a) vehicle design and b) highway form?

To what extent could shared mobility scenarios save parking spaces in cities? How will the freed space be used?

To what extent could AV use increase urban sprawl? How might one prevent this development?

To what extent can AVs contribute to urban areas and improve urban mobility systems?

How have agenda-setting, priming and framing contributed to the results of attitudinal research conducted to date?

What can be inferred from spatial and socio-demographic differences in the results of attitudinal surveys conducted to date?

What pictures of the technology and its functioning do respondents have in their minds when they answer questions about attitudes to AVs?

What will be an acceptable level of risk (eg with respect to cyber security) as AVs develop and how will this change over time?

What does the aviation industry (pilots present but largely overseeing an automated system) tell us about risk and acceptance in AVs?

What level of safety will be acceptable in AVs?

What are public attitudes to privacy as opposed to anonymity?

How should government and citizen opinion interact in determining the development and deployment of this technology/these technologies?

What is the relationship between style of governance ('light touch', interventionist) and public trust in the technology?

How would people feel (in a 'connected' world) about having their journey plans frustrated by the central control system that is 'smoothing' demand?

What does familiarity with technology mean for its acceptance and adoption? (eg can we assume that millennials will automatically be more comfortable with AVs than their parents?)

How significantly could a major incident (such as multi-fatality crash) affect popular attitudes about AVs?

How likely is that attitudes will turn against the technology?

Will people trust automated public transport vehicles, such as a bus?

How strong might opposition to AVs be and how might it be manifested?

How sophisticated can sensing and recognition systems become?

Can their imperfections be tolerated?

Is data privacy likely to be as significant in determining attitudes to AVs as personal safety/security?

Will we feel safe if sharing a vehicle with strangers but without a 
Scenes

Scenes

Scenes

Scenes

Other

Literature review

Other

Literature review

Other

Literature review

Literature review Literature review

Literature review Literature review Literature review

Literature review Mapping

Mapping

Mapping

Mapping

Mapping

Mapping

Mapping driver?

Would a large, relative decrease in road fatalities answer concerns about the deaths that might still occur with AVs?

What is the relationship between public trust, singularities (such as severe collisions) and familiarity?

Some models of $\mathrm{AV}$ operation assume the equivalent of an air traffic controller, guiding operations at a network area level. Do people feel more/less comfortable with this than a wholly automated system? How would liability be decided in the event of a crash?

How will people react to losing the ability to practise a skill (driving), the pleasure of doing it well and the sense of having some control/impact on the world?

Will AVs constitute a case of needing to 'keep up with the Jones's'? Might some groups (eg older citizens) reject driverless technology? What will be the appeal of owning a vehicle once the owner no longer drives it?

Will people accept the encroachment on data privacy that highly connected systems appear to imply?

What is a socially acceptable approach to pricing $\mathrm{AV}$ use so as not to worsen transport network performance?

Will people's acceptance of sharing data be a function of whether they are sharing with a private company or government in some form?

What level of surveillance within AVs will be necessary/justifiable? What level of surveillance around AVs (ie data collected by the vehicle concerning its surroundings) will be necessary/justifiable? Who should own and control data generated by AVs?

For what ends will the data be used?

Under what conditions and scenarios the public would be most likely to use and accept AVs?

How do non-drivers perceive Avs and what do they expect from AVs? What are the prospects for a unified communications protocol to support highly connected vehicles and who would own such a code? Can the influence of vested interests be prevented from distorting the role of government in the development process?

How can government prevent the unwanted consequences of competition between developers without at the same time losing the benefits?

Can innovation be encouraged?

How can a need for interoperability best be met whilst still allowing individual players to develop novel technological approaches? Is a common data dictionary part of the answer?

If supply of AVs cannot meet demand at some stage in the development process, is there a role for government to support production?

How to promote data sharing by companies to enable connectivity? 
Mapping

Other

Literature review

Mapping

Mapping

Mapping

Mapping

Scenes

Scenes

Scenes

Scenes

Expert interview

Expert interview

Expert interview

Literature review

Literature review

Literature review

Mapping

Mapping

Mapping

Mapping

Mapping

Mapping
Can/should government act to prevent market failure 'killing off' the technology?

How successful will OEMs and big tech firms be in resisting regulation?

How to ensure that data is shared by companies to enable connectivity?

Can smart pricing discourage certain trips (eg AV replacing a short walk to school) whilst also enabling others (access for someone with a mobility impairment)?

How might demand for automated mobility be managed to avoid a damaging excess of demand over supply?

Does greater connectedness imply greater scope for (government to) influence travel decisions and behaviour?

How might road pricing fit into an AV world and would it be more/less acceptable with the new technology?

If AVs are to be associated with reduced congestion, what operational rules will need to prevail?

Could and should government promote a more desirable ownership/use model?

What can/should government do to minimise the extent that AV use is associated with crime and/or anti-social behaviour?

How will customers' data be protected?

What is the need for driver monitoring at the various levels of automation (short of full)?

How is 'safe resumption of control' to be defined and catered for?

How can risk of cyber-crime be minimised?

Which safeguards (e.g. standards) should be established to prevent the misuse of data?

How will customers' data be protected?

With whom should the data be shared?

How will highway use be defined? Might the carriageway be delineated between AVs and other vehicles? Might there be zones in which AVs are the only vehicles permitted?

If future regulations require vehicles to have certain functionality, what will this mean for those whose vehicles don't comply?

Can (manual) driving for pleasure (eg through the Scottish glens) be accommodated in a world of AVs?

How can/will multi-level governance work with regulation re AVs?

(eg, in the UK, might there be regional or local variations in how AVs could behave?)

How could different approaches to regulation (eg laissez-faire, interventionist) affect the development of AVs and their impacts? If big tech firms (Apple, Google) are pushing the development of this technology, what is the role for government? 
Mapping Given a typical fleet renewal period of 15 years, what is a realistic profile of fleet mix over time? Does this lag imply that government should regulate sooner, rather than later?

Mapping

Mapping

Does this process require a central regulatory body?

Mapping

Do speedy software updates imply a need for a different approach to type approval?

Mapping
Mapping
Mapping
Other
Literature review
Other

Can conventional appraisal methods capture the costs and benefits of AVs - technology and regime?

Can regulation successfully stipulate minimum standards or must any standard specify fully how AVs will operate?

What will encourage/force those working with personal data to maximise its security?

Should regulation of AVs be at arm's length from government?

How will licensing work with AV use?

Can regulation anticipate AV developments?

If people have personal care budgets, will they be able to spend some of the money on transport?

Expert interview What would be the impact of setting standards relating to AVs' user interface?

Expert interview When MaaS and AVs reach their maturity, what role will the public sector play in delivery?

Expert interview What would path dependency in regulation (government not straying from familiar areas) mean for development and adoption?

Expert interview Mapping

What forms of regulation will actually prove effective?

In a world where full automation works, how will governments weigh a presumably non-zero desire for manual driving with a presumably significant safety benefit from its prohibition?

Mapping

Should a bus enjoy priority over a taxi (in an autonomous-controlled scenario)?

Mapping

Mapping

Mapping

Mapping

How should safety impacts be weighed with, say, economic impacts?

Would the state choose to provide or subsidise AV transport for certain individuals? In other words, might AVs become the new community transport?

Why shouldn't long-distance (eg overnight) travel be normal for AVs? What would stop this?

If development continues to be twin-track (OEMs making conventional cars more automated whilst Google etc aim straight for Level 5), will one type of vehicle be accorded an advantage by the traffic management system?

Mapping Will the regime allow different marques to impose different driving styles on AVs?

Mapping

Mapping

What are appropriate traffic management regimes associated with various levels of automated vehicle penetration, eg 5\%,10\% etc?

Would current norms concerning leaving minors unaccompanied translate to AVs?

Mapping What will AVs mean for the status quo with respect to subsidised transport for certain individuals?

Mapping Will AVs become the means by which Dial-a-Ride and equivalents operate? 
Scenes

Scenes

Scenes

Other

Literature review

Literature review

Expert interview

Literature review

Other

Other

Other

Literature review

Other

Other

Literature review

Literature review

Literature review

Other

Other

Literature review

Other

Literature review

Other

Expert interview

Expert interview

Mapping

Mapping

Scenes

Scenes

Scenes

Scenes
Would pricing in future take account of vehicle size?

In a mixed fleet, should AVs be differentiable from driven vehicles?

If individual preference with respect to AV use (eg not riding with strangers) is not optimal with respect to, say, traffic operation, energy use, what will determine the trade-off?

In a highly 'automated-controlled' regime, who would decide the hierarchy of journey importance and how would it be implemented?

Will public transport authorities adopt AVs as part of their offering?

If freight vehicles become automated, will staff be needed to accompany the vehicle?

In an 'automated-controlled' world, how might trips be prioritised by the central control system?

What role should AVs play in cities?

How will social norms change with the passing of time?

What does increasing urbanisation imply for the distribution of urban trip lengths?

How will the general cost of mobility change over time?

What is the future of people's desire to own things?

How much space will the average person have in future?

Will transport continue to become depoliticised?

What if the widespread strategic objective of removing traffic continues?

Is the attraction of a car as status symbol fading in the developed west?

What will be the distribution of wealth as time passes?

Can we assume that those born with technology will always embrace

it? Why shouldn't people's attitude to technology change as they age?

Can the much reported lack of interest in driving amongst young people be relied upon?

What will be the style of government in future (eg localism, centralism?) and how might this affect AV development?

Is the future one of continuing austerity?

Will funding in future be more in control of municipalities/city regions etc?

Will integration of funding allow government to move money more readily between transport and other areas?

Does an ageing population imply an ever-increasing number of people having their licences taken away?

How will the wider sharing economy play out?

Do we need the benefits of AVs to be articulated? If so, what are they?

Are AVs the latest example of boys and their toys (ie something liked because it appeals in a primal way without necessarily being strategically necessary?)

How local are ethical questions relating to AVs?

Can there be a shared vision for this technology?

What is the role of AVs in the Department for Transport's strategy? Is there a 'desirable' volume of movement? Or 'desirable' volumes of 

Other Transport practitioners tend to expect an innovation to be a response to a need or problem. AVs can be characterised as merely an opportunity. What might be the policy implications?
Expert interview Can current appraisal tools handle AV-related interventions and, if not, what is required?
Expert interview How would AV-related schemes (funded by government) compare in terms of value for money with standard transport interventions?

\section{Appendix: List of organisations participating in the study \\ Organisations participating in stakeholder workshops}

AA (Automobile Association)

Addison Lee

Bournemouth Borough Council

Bristol City Council

BVRLA (British Vehicle Rental and Leasing Association)

Campaign for Better Transport

Carplus

College of Policing

Confederation of Passenger Transport

Cycling UK

Department for Business, Innovation and Skills

Department for Transport

Department of Health

Freight Transport Association

Frost and Sullivan

Government Office for Science

House of Commons

Ipsos MORI

London Councils

Milton Keynes Council

National Composites Sector

Nesta

RAND Europe

Rees Jeffreys Road Fund

Road Safety Trust

Royal Town Planning Institute

Steer Davies Gleave

Telent

Thatcham Research

Transport for Greater Manchester

Transport for London

Transport Systems Catapult

TRL (Transport Research Laboratory)

University of Greenwich

University of Leeds Institute for Transport Studies

University of Westminster

University of York 
Urban Transport Group

Weightmans

Welsh Government

WSP

Organisations participating in expert interviews

Age UK

Future Cities Catapult

HORIBA MIRA

ITS International

Northamptonshire County Council

RAC Foundation

Toyota Research Institute

Transport Systems Catapult

University of Leeds Institute for Transport Studies

i Figure taken from the World Health Organisation,

http://www.who.int/gho/road safety/mortality/traffic deaths number/en/ accessed 8 July 2014 